\title{
A new staging system for thymoma-will it improve outcomes?
}

\author{
James Huang, MD
}

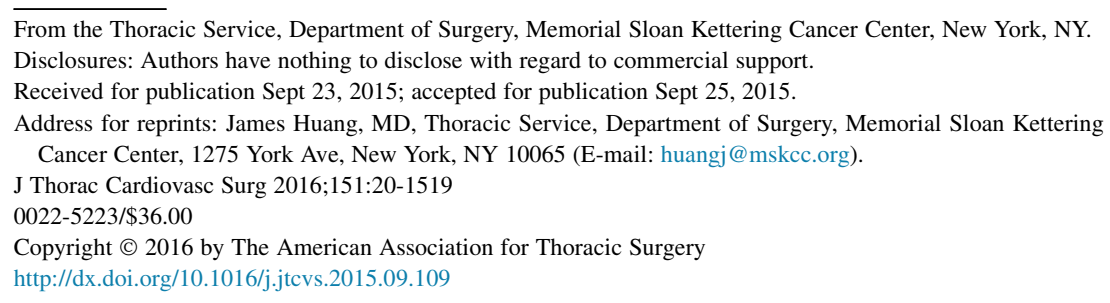

Historically, thymic tumors have intrigued clinicians, with their association with autoimmune syndromes, their peculiar behavior and penchant for pleural spread, and the heterogeneity of their histologic appearance. Their rarity has only compounded the difficulty in achieving consensus in categorizing these neoplasms, giving rise to numerous attempts at describing histologic as well as staging classifications. Through the years, many authors have offered proposals for the staging of thymic tumors, yet most have failed to gain traction. At least 14 different staging classifications have been proposed during the last 4 decades, as nicely summarized in a recent review placing them in the broader historical context. ${ }^{1}$

Thirty-four years ago, Masaoka and colleagues ${ }^{2}$ first proposed a staging system for thymoma. Although it was based on an analysis of only 93 patients, the system's ability to prognosticate has stood up well to the test of time, and the eponymous Masaoka staging system continues to be the most widely used classification today. Ambiguities with the wording of the staging system subsequently led to attempts to modify and clarify it, most notably with the revision offered by Koga and colleagues ${ }^{3}$ in 1994.

Questions about interpretation persisted, however, partly as a result of the incorporation of clinical as well as pathologic descriptors into the classification. For example, what was meant exactly by "macroscopic invasion into neighboring organs"? How does one identify a tumor that is "grossly adherent to but not breaking through mediastinal pleura"? Where is the mediastinal pleura on the specimen? Does the classification apply to thymic carcinomas as well, or only to thymomas? These nuances were itemized by Detterbeck and colleagues ${ }^{4}$ in an attempt to identify the gaps in knowledge and with an eye toward revising the staging system.

The International Thymic Malignancy Interest Group (ITMIG) arose out of a common interest in these rare tumors and a desire to promote collaboration in research. One of the primary objectives of ITMIG was the development of a new evidence-based TNM staging proposal for consideration by the American Joint Commission on

Cancer and the Union for International Cancer Control. In partnership with the International Association for the Study of Lung Cancer, ITMIG assembled a global data set of more than 6000 cases drawn from nearly 50 institutions spanning 15 countries around the world. ${ }^{6}$ That this was accomplished in just over 6 months is a testament to the engagement of ITMIG's members.

From these data emerged a new staging classification organized along the tumor, node, and metastasis axes. The $\mathrm{T}$ descriptors take on the greatest significance, because nodal and distant metastases remain uncommon, and ascend by depth of invasion into mediastinal fat (T1a), mediastinal pleura (T1b), pericardium (T2), and other adjacent organs (T3, T4). ${ }^{8}$ Importantly, the $\mathrm{T}$ descriptors are now specifically based on microscopic, pathologic assessment of invasion, rather than on the ill-defined measure of "macroscopic invasion." Mediastinal pleura and pericardium are now individually addressed, such that their prognostic significance can be more thoroughly assessed in the future. Adjacent organ invasion has essentially been divided into "more resectable" (T3) and "less or unresectable" (T4) categories.

Despite the large number of cases, the amount of available data to examine the impact of nodal and distant metastases remained quite modest, precluding the finding of any statistically significant differences. The recommendations 
therefore primarily offer the standardization of $\mathrm{N}$ and $\mathrm{M}$ descriptor levels for future data capture. ${ }^{9}$ The $\mathrm{N}$ descriptor now allows the distinction of nodal involvement by location (N1 anterior/perithymic, N2 deep intrathoracic/cervical) and provides clear annotation of anatomic boundaries. ${ }^{10}$ The $\mathrm{M}$ descriptor distinguishes between pleural and pericardial nodules (M1a) and distant metastases, including intrapulmonary metastasis (M1b). With the descriptors defined, we can now capture them going forward.

These results are the culmination of an unprecedented effort into the study of thymic malignancies, and they represent a quantum leap forward from the series of Masaoka and colleagues ${ }^{2}$ more than 3 decades ago. Notably, the analysis included thymic carcinomas and thymic carcinoids, resulting in a unified staging classification that is inclusive of all thymic malignancies. The proposal derives its strength not only from the large and diverse patient population but also from the statistical rigor of the methodology used by the Cancer Research and Biostatistics group and their cumulative experience working on lung cancer staging. ${ }^{11}$ Both survival and recurrence measures were examined as outcomes for all patients, regardless of resection status, as well as only for patients with R0 resections.

Nevertheless, because of the retrospective nature of the data collected, many gaps remain. Will we be able to identify reliably extension into mediastinal pleura pathologically (T1b)? Will we ever have enough cases of T4 invasion into aorta or myocardium to validate this descriptor, and are we truly able to confirm that pathologically? Can we accurately define nodal status, when most surgeons generally do not perform a systematic lymph node dissection routinely in thymectomies? And exactly what would a complete nodal dissection for thymic tumors entail?

Whereas all staging systems seek to delineate wellseparated prognostic groups, perhaps the greatest contribution of the new proposal is the creation of standardized nomenclature to facilitate communication and collaboration. With clear definitions of the various boundary lines, we can now begin to collect that information in a consistent manner. The next steps, of course, are to collect these data points prospectively, and this has already been initiated by ITMIG, with the creation of a prospective, webbased platform. ${ }^{6}$ Prospective data collection enables far greater detail to be captured, and the data are no longer limited to whatever was contained in existing population-based registries and institutional databases. In essence, this new proposal merely sets the stage for the next revision.

Ultimately, the pursuit of ever finer gradations and sharper separation of survival curves leads to diminishing returns, however, and one must consider the underlying purpose of these staging systems. Stage is the description of the anatomic extent of disease. But what we are trying to get at is a representation of the biology of the tumor and, from that, an assessment of the patient's prognosis. In the past, when diagnostic sophistication was limited and effective treatments were lacking, the anatomic extent of disease was a reasonable measure of prognosis. In this day and age of molecular medicine, however, we have a far greater capacity to assess biology directly. Furthermore, we are recognizing that many more factors may exert significant, if not greater, influence on the prognosis-whether patient-related factors, treatmentrelated factors, or tumor-specific factors, such as genomics. The next versions of the staging system will need to go beyond anatomic disease extent into larger prognostic models. Welcome to the post-stage era of prognostication.

\section{References}

1. Filosso PL, Ruffini E, Lausi PO, Lucchi M, Oliaro A, Detterbeck F. Historica perspectives: the evolution of the thymic epithelial tumors staging system. Lung Cancer. 2014;83:126-32.

2. Masaoka A, Monden Y, Nakahara K, Tanioka T. Follow-up study of thymomas with special reference to their clinical stages. Cancer. 1981;48: 2485-92.

3. Koga K, Matsuno Y, Noguchi M, Mukai K, Asamura H, Goya T, et al. A review of 79 thymomas: modification of staging system and reappraisal of conventional division into invasive and non-invasive thymoma. Pathol Int. 1994; 44:359-67.

4. Detterbeck FC, Nicholson AG, Kondo K, Van Schil P, Moran C. The Masaoka-Koga stage classification for thymic malignancies: clarification and definition of terms. J Thorac Oncol. 2011;6(7 Suppl 3):S1710-6.

5. Detterbeck FC, Asamura H, Crowley J, Falkson C, Giaccone G, Giroux D, et al Staging and Prognostic Factors Committee; Members of the Advisory Boards; Participating Institutions of the Thymic Domain. The IASLC/ITMIG thymic malignancies staging project: development of a stage classification for thymic malignancies. J Thorac Oncol. 2013;8:1467-73.

6. Huang J, Ahmad U, Antonicelli A, Catlin AC, Fang W, Gomez D, et al: International Thymic Malignancy Interest Group International Database Committee and Contributors. Development of the international thymic malignancy interest group international database: an unprecedented resource for the study of a rare group of tumors. J Thorac Oncol. 2014;9:1573-8. Erratum in: J Thorac Oncol. 2014;9:1804.

7. Detterbeck FC, Stratton K, Giroux D, Asamura H, Crowley J, Falkson C, et al; Staging and Prognostic Factors Committee; Members of the Advisory Boards; Participating Institutions of the Thymic Domain. The IASLC/ITMIG Thymic Epithelial Tumors Staging Project: proposal for an evidence-based stage classification system for the forthcoming (8th) edition of the TNM classification of malignant tumors. J Thorac Oncol. 2014;9(9 Suppl 2) S65-72.

8. Nicholson AG, Detterbeck FC, Marino M, Kim J, Stratton K, Giroux D, et al Staging and Prognostic Factors Committee; Members of the Advisory Boards; Participating Institutions of the Thymic Domain. The IASLC/ITMIG Thymic Epithelial Tumors Staging Project: proposals for the $\mathrm{T}$ component for the forthcoming (8th) edition of the TNM classification of malignant tumors. J Thorac Oncol. 2014;9(9 Suppl 2):S73-80.

9. Kondo K, Van Schil P, Detterbeck FC, Okumura M, Stratton K, Giroux D, et al; Staging and Prognostic Factors Committee; Members of the Advisory Boards; Participating Institutions of the Thymic Domain. The IASLC/ITMIG Thymic Epithelial Tumors Staging Project: proposals for the N and M components for the forthcoming (8th) edition of the TNM classification of malignant tumors. J Thorac Oncol. 2014;9(9 Suppl 2):S81-7.

10. Bhora FY, Chen DJ, Detterbeck FC, Asamura H, Falkson C, Filosso PL, et al Staging and Prognostic Factors Committee; Advisory Boards. The ITMIG/ IASLC Thymic Epithelial Tumors Staging Project: a proposed lymph node map for thymic epithelial tumors in the forthcoming 8th edition of the 
TNM classification of malignant tumors. J Thorac Oncol. 2014;9(9 Suppl 2): S88-96.

11. Groome PA, Bolejack V, Crowley JJ, Kennedy C, Krasnik M, Sobin LH, et al; IASLC International Staging Committee; Cancer Research and Biostatistics;
Observers to the Committee; Participating Institutions. The IASLC Lung Cancer Staging Project: validation of the proposals for revision of the T, N, and M descriptors and consequent stage groupings in the forthcoming (seventh) edition of the TNM classification of malignant tumours. J Thorac Oncol. 2007;2:694-705. 